\title{
Embodied Ways of Knowing: Revisiting Feminist Epistemology
}

\author{
Karen Barbour
}

\section{Introduction}

Feminist scholarship developed a focus on articulating women's ways of knowing and validating women's different experiences. Reading key scholars Liz Stanley and Sue Wise's (1990) substantial work on feminist praxis, I took seriously the argument that epistemology should be understood broadly as addressing the questions 'who can be a "knower", what can be known, what constitutes and validates "knowledge", and what the relationship is or should be between knowing and being' (Stanley \& Wise, 1990, p. 26). The focus of my feminist interest in epistemology thus began with my attempt to understand my role as knower, and to contribute to the development of multiple and alternative "knowledges". Occupying the margins as a dancer in academia, and also the margins of feminist research in sport, leisure and physical activity, I have nevertheless found a role in articulating embodied ways of knowing.

My intention in this chapter is to review key critiques of Western epistemology and dualistic ontology, and to discuss feminist epistemologies. These (now historical) key critiques informed the development of more recent scholarship and contributed to new feminist and phenomenological understandings of embodiment and embodied ways of knowing. ${ }^{1}$ Ultimately, my intention is to advocate for and provide an example of feminist theorizing through embodiment as a dancer that may offer insights to other embodied practitioners in sport, leisure and physical activity.

K. Barbour $(\bowtie)$

University of Waikato, Hamilton, New Zealand 


\section{Western Epistemology}

The term epistemology has been broadly used to refer to the theory of knowledge, the nature of knowing and understanding (Code, 1991; Jagger \& Bordo, 1989; Stanley \& Wise, 1990). In traditional Western philosophy, epistemology has been a transcendent, neutral pursuit, establishing the truth of knowledge claims about the objective world (Code, 1991; Jagger \& Bordo, 1989). Much of the basis of Western epistemology originated in the Enlightenment period, developed into the Cartesian tradition and took the task of epistemology to be 'to identify a method by which individual investigators may best use their faculties to gain knowledge of the objective structure of reality' (Jagger \& Bordo, 1989, p. 3).

Within Western contexts, "knowledge" was defined as this information gained through reason, which was the method of knowing (Code, 1991). Western reason required that a statement or knowledge claim be evaluated against objective standards and criteria to determine its truth. Statements that could be proved true could be accepted as fact, and as objective, universal knowledge. "Knowing" utilized both inductive and deductive reasoning as the reliable and valid methods to draw conclusions about truth claims. "Knowers" were neutral, rational and independent subjects — discoverers of truth in a world accessible through reason (Code, 1991; Flax, 1993). The pursuit of objective knowledge required a neutral subject, and therefore the differences between individual knowers were to be overcome (Jagger \& Bordo, 1989).

Alongside these epistemological assumptions, and aim for objective and universal truth, sat a dualistic ontology that constituted the basis of Western knowledge (Stanley \& Wise, 1990; Warren, 1996). This dualistic ontology can be traced back to the work of ancient Greek philosophers Plato and Aristotle, ${ }^{2}$ and is evident in the work of philosophers Descartes and $\mathrm{Kant}^{3}$ (Stanley, 1990). These underlying dualisms included knowledge/experience, mind/body, object/ subject, culture/nature, reason/emotion, thought/sensation, public/private, and universal/particular ${ }^{4}$ (Beauvoir, 1972; Grosz, 1994; Weiss, 1999). This dualistic ontology was accepted within Western knowledge and not considered problematic until feminist critique in the twentieth century (Beauvoir, 1972, 2010; Jagger \& Bordo, 1989). Feminists argued that 'these dualisms are overlaid by gender; only the first of each pair is associated with the male' (Hartsok, 1983, p. 297). Consequently, Western knowledge was revealed as based on a dualistic ontology that privileged men and associated qualities, and utilized a logic of domination which resulted in the assumption that men were superior to women, and that knowledge and mind were superior to experience and body (Code, 1991; Warren, 1996). 


\section{Feminist Challenges to Western Knowledge}

Feminism is the name for the multitude of perspectives of women who have been concerned to critique what counts as knowledge, what knowledge counts, and who can know (Du Plessis \& Alice, 1998; Reinharz, 1992). Central to many feminist perspectives has been an argument that the epistemological project to articulate neutral, objective and transcendent knowledge has privileged the understandings of dominant Western white men (Belenky, Clinchy, Goldberger, \& Tarule 1986; Gatens, 1995; Grosz, 1994). Thus, the claim that Western "knowledge" is not gender neutral is central to feminisms (Beauvoir 1972, 2010; Jagger \& Bordo, 1989). However, a simple resolution to the dominance of dualistic ontology, the overwhelming bias of knowledge, and the exclusion of body and experience, has not been easily realizable.

Feminists saw that what was required was not simply the addition of women's understandings into "knowledge", but also a reconstruction and acceptance of multiple "knowledges" (Davion, 1994). Articulation of women's lived experiences was especially important as women sought to reconstruct knowledge, power and authority in relation to their different experiences. The feminist slogan "the personal is the political" indicated recognition that the individual experiences of women could be understood as socio-culturally and politically contextual (Mills, 1997). Sara Mills commented that 'those problems which many women once considered to be their fault ... have come to be seen ... as problems which are structural and therefore political' (1997, p. 79). The particular experiences of an individual woman thus determine her priorities for feminist action and her interests in specific feminist theories.

\section{Feminist Epistemology}

While there has been debate between feminists about whether there can be feminist epistemology (Code, 1991; Harding \& Hintikka, 1983; Jagger \& Bordo, 1989), it certainly seemed important that epistemology be more broadly understood than merely as rational thinking and cognition. For me, epistemology is about thinking differently about how I know, and about understanding knowledge in my specific context, evaluating it on its own terms and in relation to myself as a knower (Goldberger, Tarule, Clinchy, \& Belenky, 1996; Stanley \& Wise, 1990).

Feminist critiques revealed masculine bias and the constructed nature of knowledge. Because the beliefs, practices and experiences of individual 
women and people other than white Western men had been left out of dominant "knowledge", some feminists described "knowledge" as alienated from its context (Stanley, 1990). Such "epistemologies that cannot account for women's experiences, and/or that denigrate their experiential knowledge have to be displaced' (Code, 1991, p. 251) — reconceived entirely by revealing and reshaping underlying assumptions (Keller \& Grontkowski, 1983). Feminists have thus argued that gender and individual identity are significant in the process of becoming a subject and a knower (Flax, 1993). Being a subject or knower entails multiplicity and diversity, and recognition of the ways in which socio-cultural, political, historical and embodied differences structure the knower (Hawkesworth, 1989). While the individual woman is contextualized, 'she none the less exists as a thinking, feeling subject and social agent, capable of resistance and innovations produced out of the clash between contradictory subject positions and practices' (Weedon, 1987, p. 125). Subjectivity thus can be redefined as constructed and socially produced rather than totally biologically determined. Conceived this way, subjectivity is incomplete, heterogeneous (Flax, 1993) and constantly shifting. The "subject" is thus an unstable, fragmented and fluid notion, rather than a single and unified identity constant over time.

Rather than only occurring through reasoning of a neutral subject, knowing can occur through experiencing. In this sense, knowing is a practice rather than simply a method of deductive and inductive reasoning. Feminists understood knowledges as conventional rather than transcendent, and as based on the 'judgements of a community of fallible inquirers' (Harding \& Hintikka, 1983; Hawkesworth, 1989, p. 549). As Code defined it 'knowledge is an intersubjective product constructed within communal practices of acknowledgment, correction and critique' (1991, p. 224). Recognition of different knowledges, alternative ways of knowing and the relevance of the particular knower, is crucial from a feminist perspective. In recognizing difference, knowledge may be grounded in lived experiences and built out of the experiences of many different people.

Thus, the feminist challenge to Western epistemology has been to reveal the constructed nature and male bias of "knowledge", to recreate "knowledges" to include multiple perspectives, and to validate women as knowers. Feminist researchers, including Mary Belenky, Blythe Clinchy, Nancy Goldberger and Jill Tarule (1986), undertook research specifically on women's ways of knowing. 


\section{Women's Ways of Knowing}

Beginning from the premise that much of the work on ways of knowing has focused on the experiences of white Western men, Belenky, Clinchy, Goldberger, and Tarule (1986) undertook extensive interviewing with many different American women to listen to their experiences and to understand their epistemological assumptions. The authors were able to articulate five epistemological positions or strategies that characterized the women in their study (Goldberger et al., 1996). They were careful to point out that the positions they outlined were not universal, fixed or exhaustive, and not necessarily exclusive to women (Belenky et al., 1986). They also acknowledged that these positions 'cannot adequately capture the complexities and uniqueness of an individual woman's thought and life' (Belenky et al., 1986, p. 15). They offered five epistemological strategies, summarized as follows:

1. Silence-woman experiences herself as mindless and voiceless, dependent on external authority.

2. Received knowledge-woman conceives of herself as capable of receiving and possibly reproducing knowledge from authority, but not of creating her own.

3. Subjective knowledge-woman conceives of truth and knowledge as personal, private and subjectively known or intuitive.

4. Procedural knowledge-woman is learning and applying outside procedures for accessing and communicating knowledge.

5. Constructed knowledge-woman views all knowledge as contextual and experiences herself as creator of knowledge, valuing both her own and objective strategies for knowing. (Belenky et al., 1986)

Belenky et al. (1986, p. 133) commented that the 'quest for self and voice' was a central motivation in the transformation women experienced in developing their ways of knowing. As a result, many feminists (Goldberger, 1996) have understood the epistemological positions as a developmental scheme, ${ }^{5}$ although later research framed them more clearly as epistemological strategies from which women might select.

The articulation of constructed knowing (the fifth epistemological position) resonated for me with feminist creative and emancipatory agendas, in the sense that women who attempted to integrate their own and other voices 'had learned the profound lesson that even the most ordinary human being is engaged in the construction of knowledge' (Belenky et al., 1986, p. 133). 
The authors suggested that women came to constructed knowledge 'as an effort to reclaim the self by attempting to integrate knowledge they felt intuitively was important with knowledge they had learned from others' (Belenky et al., 1986, p. 143). Such women were characterized by self-reflectiveness and selfawareness, a high tolerance of ambiguity, awareness of the inevitability of conflict, attempts to deal with the rich complexity of life as a whole and the desire to share their knowledge in their own way. Belenky et al. suggested that

Once knowers assume the general relativity of knowledge, that their frame of reference matters and that they can construct and reconstruct frames of reference, they feel responsible for examining, questioning, and developing the systems that they will use for constructing knowledge. (1986, pp. 138-139)

Such knowers asked questions about the nature of knowledge, assessing 'the appropriateness and utility of a particular way of knowing given the moment, situation, cultural and political imperatives, and relational and ethical ramifications' (Goldberger, 1996, p. 356). They became 'passionate' knowers, 'weaving their passions and intellectual life' together (Belenky et al., 1986, p. 141; Goldberger, 1996).

There were valuable critiques by feminists of these women's ways of knowing, such as the need to avoid essentializing women's knowing, the potential misrepresentation of the multiplicity of women's knowing by white educated feminists, the potential slide into subjective relativism, and the value of women's ways of knowing as a developmental scheme (Code, 1991; Goldberger et al., 1996). However, as Goldberger commented, 'When context is factored into the study of knowing, one begins to see the advantages of thinking of five categories as strategies for knowing (rather than person types)' (1996, p. 362). Individuals might then choose and use different strategies depending on their personal contextual requirements.

Belenky et al. (1986) have also been criticized for assuming that the women they studied were fixed, unitary subjects who were capable of giving authentic reports about their knowing (Code, 1991). However, by commenting on the knower's many alternative strategies for knowing, Belenky et al. (1986) reveal that she is open to shifts and radical changes in how she knows and what she knows. She has no "authentic" voice, or alternatively, her voice is "authentic" in as much as any voice ever could be. The subject cannot be a fixed and unitary one, as Belenky et al. (1986) described the women in their study, if they are also open to constant epistemological shifts and changes.

Continuing this research, Nancy Goldberger (1996) and Elizabeth Debold, Deborah Tolman, and Lyn Brown (1996), began investigation into bodily 
ways of knowing and knowledge. They were interested in knowledge that was grounded in bodily experiences, sensations and cues. Such knowledge was seen as rich, complex and non-propositional, and potentially avoided reinscribing the knowledge/experience and mind/body dualisms (Goldberger, 1996). Bodily knowing has been explored by others seeking to share women's sensory lived experiences in movement, as I will discuss below. However, before I offer any discussion of bodily and embodied knowing, I review some understandings of experience developed in phenomenology.

\section{Phenomenological and Feminist Understandings of Movement Experience}

Within the many theoretical perspectives of Western thinking, phenomenology was one approach that recognized experience as a way that individuals come to know: a "touchstone" of knowledge (Grosz, 1994; Nettleton \& Watson, 1998). Phenomenology offered an "attitude" or orientation of paying attention to the world as lived and experienced, and this attitude offered the basis for an epistemology, theoretical perspective, methodology, method or a combination of these (Allen-Collinson, 2011). Within phenomenological writing, the work of Simone de Beauvoir $(1972,2010)$ and Maurice Merleau-Ponty $(1962,1964 a$, 1964b) were particularly relevant in offering gendered and situated understandings of lived experience. While phenomenology has remained a marginalized perspective, likely due to its focus on lived body and lived experience, it offers

an epistemology and a descriptive method that resonate with many central feminist theoretical concerns: it eschews rationalism and objectifying mind-body dualism, and instead invites a focus on embodied, situated, immediate and often more affective forms of experience. (Kruks, 2014, p. 76)

Phenomenologist Maxine Sheets-Johnstone (1999) contributed a great deal to understanding the experience of movement and bodily knowing. She developed Merleau-Ponty's (1962, 1964a) phenomenological work significantly, arguing for the primacy of movement over the primacy of perception. She commented that perception results from movement, and thus movement was 'the originating ground of our sense-makings' (Sheets-Johnstone, 1999, p. 161). Sheets-Johnstone (1999) argued that humans learn about themselves and others initially through moving-by attending to bodily sensations of movement, rather than by looking and seeing what is moving. Movement is experienced through the kinesthetic sense, providing the individual with information about 
space, time, movement and objects, and their relationship to these things, as it changes in the moment (Stinson, 1995). The kinesthetic sense is fundamental to knowledge of what we are, to our basic understanding of the world, and our ability to move knowledgeably in the world (Sheets-Johnstone, 1999). In this sense, movement experience is of profound epistemological significance (SheetsJohnstone, 1999). Sheets-Johnstone writes

A dynamically attuned body that knows the world and makes its way within it kinetically is thoughtfully attuned to the variable qualia of both its own movement and the movement of things in its surrounding word - to forceful, swift, slow, straight, swerving, flaccid, tense, sudden, up, down and much more. Caught up in an adult world, we easily lose sight of movement and of our fundamental capacity to thinking in movement. Any time we care to turn our attention to it, however, there it is. (Sheets-Johnstone, 1999, pp. 516-517)

Sheets-Johnston offered particularly influential description and theorizing of dance improvisation as thinking in movement in which there is no separation between thinking and doing, and between sensing and moving (SheetsJohnstone, 1999; first published in 1966). Sheets-Johnstone (1999) stimulated further phenomenological and feminist scholarship, particularly in dance (including Albright, 1997; Barbour, 2002, 2011a; Fraleigh, 1987; Stinson, 1995).

A significant phenomenologist in women's movement, Iris Marion Young (1980) drew on Merleau-Ponty (1962, 1964a) and feminist Simone de Beauvoir (1972) to develop an understanding of women's lived bodily experience. Young wished to articulate the specifics of women's lived movement experience and embodiment, something feminists had noted that MerleauPonty did not do (Grosz, 1994). Young focused on movement experiences aimed at achieving specific tasks, such as 'throwing like a girl', and outlined basic modalities of feminine body comportment (Young, 1980). She argued that a common experience of many Western women involved being both a subject for herself and an object. This kind of experience meant that women often tended to mediate their actions by imagining how they appeared as objects to others, at the same time that they also experienced their actions as intentional subjects (Weiss, 1999; Young, 1980). Such experiences resulted in a kind of discontinuity between a woman's intention as a subject undertaking a task and her action as an object that she saw from an external perspective.

According to Young (1980), feminine bodily experience was: intentionally inhibited (by perception of her own inability to achieve the task undertaken); ambiguously transcendent (by concentrating on her action in one part of the 
body while the rest remained uninvolved); and had a discontinuous unity (by breaking her connection between intention and action, between possibility and actual bodily achievement). Women thus did not utilize their full spatial and lateral movement potential (Young, 1980). Young concluded her comments by stating that 'An essential part of the situation of being a woman is that of living with the ever-present possibility that one will be gazed upon as a mere body, as shape and flesh that presents itself as the potential object of another subject's intentions and manipulations, rather than as a living manifestation of action and intention' (1998a, p. 270). Young's work set the precedent for feminist study of women's movement experiences separately from those of men $(1980,1998 \mathrm{~b})$ and offered a basis from which to research women's sport, dance, leisure and physical activity. For example, Young's work (1980, 1998b) was extended in research on women's dance (Albright, 1997; Barbour, 2002, 2011a) and climbing (Chisholm, 2008).

In researching women's contemporary dance, Ann Cooper Albright (1997) had applied Young's work to analyzing particular artists, arguing that some dancers were able to expand the norms of feminine movement by demonstrating clear directed energy, clarity of weight, spatial intention and movement flow. According to Albright (1997), such dancing was responsive, enduring, able to accommodate change and could offer a more profound experience for an audience. While based on other women's lived experiences, this analysis provided inspiration for my phenomenological research into my own and other women's lived experiences as solo dancers. A further inspiration was Young's (1998b) criticism of her own work in which she suggested beginning with acknowledging that often multiple things happen at once for many women; beginning with multiplicity rather than singularity. My improvisational practices and choreographic strategies in solo dance had allowed me to develop movement that had multiple intentions; to develop kinesthetic empathy with my experiences through the use of everyday, pedestrian and gestural movement; to subvert and resist expectations of the dancer; to challenge or change stereotypical feminine movement and movement qualities; and ultimately, to be an embodied expression of my lived experience (Barbour, 2002, 2011a). Thus, multiplicity was a feature of my movement.

I also valued the way in which dance-making processes and performances allowed me to be both receptive and responsive to my lived experiences. I aimed to receive and integrate information from multiple sources, including moment-to-moment changes and understandings developed during performing, audience responses, events in my life, and choreographed movement (Sheets-Johnstone, 1999). I then aimed to respond to these multiple sources in whatever manner I felt appropriate in the given moment. I had the opportunity 
to improvise, adapt and respond, both thinking in and about movement as I danced (Sheets-Johnstone, 1999). Instead of experiencing inhibited, partially expressive movement and feeling disconnection between my intention and action as described in Young's modalites of feminine movement, and instead of only creating a fixed singular plan, finding control and developing singular intention (1980, 1998a), I experienced multiplicity in intention, and receptivity and responsiveness in dancing. As I was thinking in movement, I experienced alternative modalities of feminine movement to those proposed in Young's analysis (Barbour, 2002, 2011b). My feminist narratives of experience intersected with phenomenological descriptions and auto-ethnographic representations of movement.

In a different movement context, Dianne Chisholm's (2008) analysis of 'climbing like a girl' offered a descriptive and insightful example of phenomenological and feminist theorizing. Chisholm critiqued Young's early work (Young, 1980), arguing that her 'focus on feminine motility and spatiality precludes analysis of how girls and women can and do embody free movement despite masculine domination' in contemporary life (2008, p. 11). She draws attention to the evolving social-cultural contexts in which women now move, arguing that Young's analysis of feminine bodily movement as intentionally inhibited, ambiguously transcendent and discontinuous is no longer typical (2008). Drawing on interviews with and the autobiography of free climber Lynn Hills (2002), Chisholm argues that women may develop alternative modalities of feminine movement involving reach, coordination, flow, freedom and synesthesia, both as an "ascent" within climbing and as a feminist way of moving in the world (Chisholm, 2008). Hill's writing offers a rich example of a woman who 'habituates her body to dancing on rock with a full-body reach and a flowing choreography of moves that extend her direction of her intention over thousands of vertical feet', illustrating how 'women can, by cultivating the body's full and free movement, surmount the gender limits of their situation' (Chisholm, 2008, p. 35). Chisholm's (2008) analysis of Hill's (2002) lived experiences as a feminist and phenomenologist supports understandings of women's movement in climbing. Albright's (1997), Chisholm's (2008) and my own analyses (Barbour, 2002, 2011a) draw richly descriptive accounts of movement experiences together with feminist and phenomenological theorizing by Beauvoir (1972), Merleau-Ponty $(1962,1964 a)$ and Young (1980), to contribute new understandings of women's lived movement experiences.

Other feminist and phenomenological research in lived movement experience has emerged more recently and is exemplified in the work of Jacquelyn Allen-Collinson on long-distance running $(2008,2011)$ and Jayne Caudwell on rowing (2014). Both are interested in "mundane" and repetitive movement 
within their own everyday lived experiences in their specific contexts. Acknowledging women's vulnerability to harassment in public spaces as part of her socio-cultural and political context, Allen-Collinson writes: 'My running in public space is thus lived and felt at the individual, subjective level, but is also deeply structurally-shaped by my difficulty, as a woman, in securing "an undisputed right" to occupy that space' (2011, p. 308). Allen-Collinson's descriptions illustrate her auto-phenomenographic approach to her lived experiences of everyday distance running (2011). Caudwell (2014) describes the pleasures of rowing, weaving rich phenomenological descriptions with theory in auto-ethnography that evokes her experience on the page as she seeks to understand the role of repetitive movement in women's mental health:

sustained rows on a rowing machine are not dull and unsensual, they are polydimensional affairs and my pleasures are embodied, sensate and visceral. The flows of bodily movement require, despite their habitual and repetitive nature, open possibilities for the aesthetic, incandescent, reflexive and rhythmic. My curvilinear mundane motion becomes ambivalent, fluid and labile. The ordinariness of this repetitive physical activity is punctuated by flows of enjoyment and satisfaction. (2014, pp. 6-7)

Both Allen-Collinson (2008, 2011) and Caudwell (2014) offer phenomenological descriptions of women's lived experiences that attest to the different ways in which women move through the world, and engage with expanding theory and representational methods in feminist research. In this sense, these authors build upon the project begun by Beauvoir $(1972,2010)$ in deliberately contextualizing feminist theorizing in women's lived experiences.

Feminist and phenomenological research has validated investigating women's lived movement experiences as a method of gaining knowledge, and to which understandings of the lived body and embodiment are intimately tied.

\section{Feminist Understandings of Mind/Body and Embodiment}

Feminist critiques of mind/body dualism aimed to refigure the body at the centre of understandings of subjectivity and knowing. Like Merleau-Ponty (1962, 1964a), Elizabeth Grosz worked with the phenomenological notion of a lived body, as opposed to a corpse. She argued that 'philosophy has established itself on a profound somatophobia' (1994, p. 5) and aimed instead to develop an alternative understanding of bodily subjectivity. Development of 
alternative understandings of bodies engaged a number of key feminists (Bigwood, 1991; Braidotti, 1994; Grosz, 1994; Irigaray, 1985; Young, 1980, 1998a), as well as more recent scholars. ${ }^{6}$

Elizabeth Grosz argued that bodies not only had 'all the explanatory power of minds', but they also immediately drew attention to the question of gender, and other markings of race and age (1994, p. vii). Grosz continued: 'There are always only specific types of body, concrete in their determinations, with a particular sex, race, and physiognomy' (1994, p. 19). Thus, the specifics of difference are central to understanding individuals. Difference has to do both with the corporeal aspects of an individual, and with the 'manner in which culture marks bodies and creates specific conditions in which they live and recreate themselves' (Gatens, 1995, p. 71). The body is continually both in the process of being shaped by social practices, and at the same time, the means by which we are able to express our resistance to socio-cultural and bodily norms (Bigwood, 1991; Braidotti, 1994; Gatens, 1995). Such lived bodies strain at the seams of socio-cultural and biological fabric, being unstable and open to change; always in a process of becoming, rather than existing as a fixed entity (Albright, 1997; Diprose 1994/1995; Grosz, 1994; Weiss, 1999). Detailed feminist understandings of lived bodies in their specific instances revealed the effects both of cultural construction and of corporeality.

Feminist attention to the specificity of different individuals and to particular lived bodies (Braidotti, 1994; Flax, 1993; Grosz, 1994; Nettleton \& Watson, 1998; Weiss, 1999) aligned with phenomenological understandings that every person is uniquely embodied and that embodiment is the existential condition of being a person (Merleau-Ponty, 1962). Embodiment neither refers exclusively to, nor privileges natural/corporeal or cultural/social understandings. This is an experientially grounded view of an embodied person, as 'from this viewpoint, meaning inheres in our bodily behaviours and its gestural significance rather than being the product of some prior disembodied "Cogito" (Williams \& Bendelow, 1998, p. 8). This view requires recognition that to be a person, you are necessarily only able to exist and to know anything, as a result of being embodied.

From my perspective, embodiment incorporates many things as one: a person's biological (somatic), intellectual, emotional, bodily, artistic and spiritual experience, within their cultural and geographical location. Embodiment is not completely arbitrary - it includes recognition of individual difference in terms of race, gender, sexuality, ability, history and culture. "Embodiment" thus indicates the holistic experiencing, living subject and avoids the tendency to reinscribe the biological/cultural distinction. 


\section{Embodied Ways of Knowing}

These feminist critiques of dominant Western knowledge provided the basis for new foci on alternative feminist "knowledges", and by prioritizing lived experience and embodiment, feminists began to fulfil the potential of the "personal as the political". In drawing these feminist endeavours together, I use the phrase "embodied ways of knowing" to indicate my alternative understandings of "knowledge" and "body". Just as embodiment acknowledges individual differences as a result of socio-cultural and corporeal aspects and location, embodied ways of knowing incorporates individual differences in knowing also. Individual embodied differences are not denied in the pursuit of knowledge or the quest for self, but are brought to the forefront, and gender differences are central.

Developing the work of Belenky et al. (1986), I offered this possible sixth epistemological strategy:

6. Embodied knowledge-woman views all knowledge as contextual and embodied. She experiences herself as creator of, and as embodying knowledge, valuing her own experiential ways of knowing and reconciling these with other strategies for knowing, as she lives her life.

An individual woman using an embodied way of knowing attempts to understand knowledges as constructed (Belenky et al., 1986), and further, as something that she embodies; that she experiences and lives. She attempts to integrate the knowledges that she feels intuitively are important with what she has learned from others, and with a conscious awareness of how she embodies these knowledges. She aims to weave knowledges together with her passions, experiences and individuality. For an individual woman using an embodied knowledge strategy, living with alternative understandings to dominant knowledge will likely create challenges and tensions that she will have to resolve throughout her life. Resolutions will not come only through rationalization or intuition, but through embodying and living out the possibilities. In living out the possibilities, she will necessarily come to discard knowledge that is not liveable.

Using an embodied knowing strategy, I theorized that a feminist might resist and deconstruct dominant and oppressive stereotypes of femininity, recreating herself differently as she lives out the possibilities. I used theword "recreating" to indicate the process by which a woman might use embodied ways of knowing to creatively adapt personal beliefs and behaviours in order to resolve the 
tensions inherent in being a woman in a patriarchal context (Barbour, 2002, 2004, 2011a, 2011b). This may well be a lifelong feminist process. Interrogation of her own daily behaviour and movement, her moral and political commitments, her spiritual beliefs, her artistic practice, her employment choices, her relationships with other individuals, with dominant Western culture and her geographical environment, will involve a high degree of sensitivity and scepticism. In her recreations of herself as a woman, she will experience intellectual, spiritual, artistic, physical and emotional tensions arising from her alternative perspectives and practices of femininity. She will need to be articulate and compassionate in her embodied expression of her recreated self. And she will need extraordinary passion and commitment to live out her solutions. This, I suggest, is an embodied way of knowing herself as a woman.

In the context of my own research in embodied ways of knowing in dance, I have considered feminist choreographic practices in dance making. This immersion in the lived experience of dancing has led to recreations of practice for both live performance and for digital dance making, and also within improvisational dance practices. Immersion in the somatic, sensory-embodied experiences of dance have also offered opportunities to reconsider how I teach movement.

It seemed to me that a creative and artistic sensibility would be invaluable in embodied ways of knowing. In particular, a greater level of sensitivity to personal experience, and relationships with others and the world would be crucial. Particular artistic and movement practices and life choices might allow an individual to enhance her sensitivity and cultivate more sustainable relationships with others and with local environments. For these reasons, I think individual women may have unique alternative possibilities for recreations of femininity in their lives, and a broader range of embodied expressive strategies than are offered in traditional Western epistemology.

The research literature on women's movement not only draws on the sharing of rich phenomenological and feminist first-person descriptions of lived experience, but also engages creatively with narratives, poetry, auto-phenomenography, auto-ethnography and performance. To paraphrase Simone de Beauvoir (1972), creative representations (in literature, performance and/or research) offer the opportunity to reflect on personal experiences, share empathetically in the experiences of another and to experience another's truth as one's own-an epistemological enactment of "the personal as the political". 


\section{Summary}

With reference to a range of feminist writers who have critiqued and deconstructed Western "knowledge" and dualisms, I have explored some historical critiques and key understandings of women's ways of knowing and embodiment. My exploration led me to articulate the possibilities for understanding ways of "knowing" more broadly than simply as "reasoning", reflecting the research of Belenky et al. (1986) and Goldberger et al. (1996), and phenomenologists Young (1980, 1998a) and Sheets-Johnstone (1999). Exploring feminist understandings of embodiment, my interests turned to articulating embodied ways of knowing. Investigating women's lived movement experiences, I have argued that feminist, phenomenological and embodied perspectives and methodologies are appropriate. I suggested that embodied ways of knowing are invaluable to feminists throughout their lifetimes. How such embodied ways of knowing play out in our everyday lives as active women may thus be a focus for future creative research within the fields of dance, sport, leisure and physical activity.

\section{Notes}

1. Portions of this chapter are based upon my doctoral research (Barbour, 2002) and published works (Barbour, 2004, 2011a, 2011b) re-used with permission.

2. Plato lived 428-348 BC and Aristotle lived 384-322 BC (Allen, 1966).

3. Rene Descartes lived 1596-1650 (Descartes, 1968) and Immanuel Kant lived 1724-1804 (Scruton, 1982).

4. These dualisms are debated at length in feminist literature.

5. For discussion about women's ways of knowing as a developmental scheme, see Code (1991).

6. The feminists here represent a range of feminist perspectives and each offered a slightly different understanding of body. I adapted understandings as relevant.

\section{References}

Albright, A. C. (1997). Choreographing difference. The body and identity in contemporary dance. Hanover, NH: Wesleyan University Press.

Allen-Collinson, J. (2008). Running the routes together: Corunning and knowledge in action. Journal of Contemporary Ethnography, 37(1), 38-61.

Allen-Collinson, J. (2011). Feminist phenomonology and the woman in the running body. Sport, Ethics and Philosophy, 5(3), 297-313. 
Allen, R. E. (Ed.). (1966). Greek philosophy: Thales to Artistotle. New York: The Free Press.

Barbour, K. N. (2002). Embodied ways of knowing: Women's solo contemporary dance in Aotearoa. PhD thesis, Faculty of Education, University of Waikato, New Zealand.

Barbour, K. N. (2004). Embodied ways of knowing. Waikato Journal of Education, 10, 227-238.

Barbour, K. N. (2011a). Dancing across the page: Narrative and embodied ways of knowing. Bristol, UK: Intellect Books.

Barbour, K. N. (2011b). Writing, dancing, embodied knowing: Autoethnographic research. In D. Davida (Ed.), Fields in motion: Ethnography in the worlds of dance (pp. 101-117). Canada: Wilfrid Laurier University Press.

de Beauvoir, S. (1972). The second sex (H. M. Parshley, Trans.). Harmondsworth: Penguin.

de Beauvoir, S. (2010). The second sex (C. Borde \& S. Malovany-Chevallier, Trans.). New York: Knopf.

Belenky, M. F., Clinchy, B. M., Goldberger, N. R., \& Tarule, J. M. (Eds.). (1986). Women's ways of knowing. The development of self, voice and mind. New York: Basic Books.

Bigwood, C. (1991). Renaturalizing the body (with the help of Merleau-Ponty). Hypatia, 6(3), 54-73.

Braidotti, R. (1994). Nomadic subjects. Embodiment and sexual difference in contemporary feminist theory. New York: Columbia University Press.

Caudwell, J. (2014). 'Feeling blue': The ordinary pleasures of mundane motion. Qualitative Research in Sport, Exercise and Health, (ahead of print), 2-12.

Chisholm, D. (2008). Climbing like a girl: An exemplary adventure in feminist phenomenology. Hypatia, 23(1), 9-40.

Code, L. (1991). What can she know? Feminist theory and the construction of knowledge. New York: Cornell University Press.

Davion, V. (1994). Is ecofeminism feminist? In K. Warren (Ed.), Ecological feminism (pp. 8-28). London \& New York: Routledge.

Debold, E., Toman, D., \& Brown, L. M. (1996). Embodying knowledge, knowing desire. Authority and split subjectivities in girl's epistemological development. In N. R. Goldberger, J. Tarule, B. Clinchy, \& M. Belenky (Eds.), Knowledge, difference and power. Essays inspired by women's ways of knowing (pp. 85-125). New York: Basic Books.

Descartes, R. (1968). Discourse on method and the meditations (F. E. Sutcliffe, Trans.). England: Penguin Books.

Diprose, R. (1994/1995). Performing body-identity. Writings on Dance, 11/12, 6-15

Du Plessis, R., \& Alice, L. (1998). Feminisms, connections and differences. In R. Du Plessis \& L. Alice (Eds.), Feminist thought in Aotearoa, New Zealand, connections and differences (pp. xv-xx). Auckland, New Zealand: Oxford University Press.

Flax, J. (1993). Disputed subjects: Essays on psychoanalysis, politics and philosophy. London \& New York: Routledge. 
Fraleigh, S. H. (1987). Dance and the lived body. A descriptive aesthetics. Pittsburg, PA: University of Pittsburg Press.

Gatens, M. (1995). Imaginary bodies. Ethics, power and corporeality. London \& New York: Routledge.

Goldberger, N. R. (1996). Looking backward, looking forward. In N. R. Goldberger, J. M. Tarule, B. M. Clinchy, \& M. F. Belenky (Eds.), Knowledge, difference and power. Essays inspired by women's ways of knowing (pp. 1-17). New York: Basic Books.

Goldberger, N. R., Tarule, J. M., Clinchy, B. M., \& Belenky, M. F. (Eds.). (1996). Knowledge, difference and power. Essays inspired by women's ways of knowing. New York: Basic Books.

Grosz, E. (1994). Volatile bodies. Toward a corporeal feminism. Australia: Allen \& Unwin. Harding, S., \& Hintikka, M. B. (Eds.). (1983). Discovering reality. Feminist perspectives on epistemology, metaphysics, methodology and philosophy of science. Dordretch, Holland, Boston \& London: D. Reidel Publishing Co..

Hartsok, N. C. M. (1983). The feminist standpoint: Developing the grounds for a specifically feminist historical materialism. In S. Harding \& M. B. Hintikka (Eds.), Discovering reality. Feminist perspectives on epistemology, metaphysics, methodology and philosophy of science (pp. 283-310). Dordretch, Holland, Boston \& London: D. Reidel Publishing Co..

Hawkesworth, M. E. (1989). Knowers, knowing, known: Feminist theory and claims of truth. Signs: Journal of Women in Culture and Society, 14(3), 533-557.

Hills, L. (2002). Climbing free: My life in the vertical world. New York: W.W. Norton. Irigaray, L. (1985). This sex which is not one (C. Porter, Trans.). Ithaca, NY: Cornell University Press.

Jagger, A. M., \& Bordo, S. R. (Eds.). (1989). Gender/body/knowledge. Feminist reconstructions of being and knowing. New Brunswick \& London: Rutgers University Press.

Keller, E. F., \& Grontkowski, C. R. (1983). The mind's eye. In S. Harding \& M. B. Hintikka (Eds.), Discovering reality. Feminist perspectives on epistemology, metaphysics, methodology and philosophy of science (pp. 207-224). Holland, Boston \& London: D. Reidel Publishing Co..

Kruks, S. (2014). 'Women's lived experience': Feminism and phenomenology from Simone de Beauvoir to the present. In M. Evans, C. Hemmings, \& M. Henry (Eds.), The SAGE handbook of feminist theory (pp. 75-92). London: Sage Publications Ltd.

Merleau-Ponty, M. (1962). The phenomenology of perception (C. Smith, Trans.). London: Routledge \& Kegan Paul.

Merleau-Ponty, M. (1964a). The primacy of perception. Evanston, IL: Northwestern University Press.

Merleau-Ponty, M. (1964b). Signs (R. C. McCleary, Trans.). Evanston, IL: Northwestern University Press.

Mills, S. (1997). Discourse. London \& New York: Routledge.

Nettleton, S., \& Watson, J. (Eds.). (1998). The body in everyday life. London: Routledge. 
Reinharz, S. (1992). Feminist methods in social research. New York: Oxford University Press.

Scruton, R. (1982). Kant. London: Oxford University Press.

Sheets-Johnstone, M. (1966). The phenomenology of dance. Madison \& Milwakee, WI: The University of Wisconsin Press.

Sheets-Johnstone, M. (1999). The primacy of movement. Amsterdam \& Philadelphia: John Benjamins Publishing Co..

Stanley, L. (Ed.). (1990). Feminist praxis: Research, theory and epistemology in feminist sociology. London: Routledge.

Stanley, L., \& Wise, S. (1990). Method, methodology and epistemology in feminist research processes. In L. Stanley (Ed.), Feminist praxis: Research, theory and epistemology in feminist sociology (pp. 20-60). London: Routledge.

Stinson, S. W. (1995). Body of knowledge. Educational Theory, 45(1), 43-54.

Warren, K. J. (1996). Ecological feminist philosophies. Bloomington, IN: Indiana University Press.

Weedon, C. (1987). Feminist practice and poststructuralist theory. Oxford: Basil Blackwell.

Weiss, G. (1999). Body images. Embodiment as intercorporeality. New York \& London: Routledge.

Williams, S. J., \& Bendelow, G. (1998). The lived body. Sociological themes, embodied issues. New York: Routledge.

Young, I. M. (1980). Throwing like a girl. In I. M. Young (Ed.), Throwing like a girl (pp. 141-159). Bloomington, IN: Indiana University Press.

Young, I. M. (1998a). Situated bodies. Throwing like a girl. In D. Welton (Ed.), Body and flesh. A philosophical reader (pp. 259-273). Oxford: Blackwell.

Young, I. M. (1998b). "Throwing like a girl”: Twenty years later. In D. Welton (Ed.), Body and flesh. A philosophical reader (pp. 286-290). Oxford: Blackwell.

Karen Barbour is Associate Professor in The School of Arts at the University of Waikato, New Zealand. Her research focuses on embodied ways of knowing, particularly feminist choreographic practices in dance theatre, site-specific, digital dance and pedagogical movement contexts. Karen presents regularly at international dance conferences and has published in a range of journals. Her book publications include Dancing across the Page: Narrative and Embodied Ways of Knowing (Barbour, 2011) and Ethnographic Worldviews: Transformations and Social Justice (Rinehart, Barbour, and Pope, 2014). She is editor of the journal Dance Research Aotearoa. 